Demiryolu Mühendisliği

Ocak 2021

Say1:13, Sayfa: 43-52

Araştırma Makalesi
Railway Engineering

Jan. 2021

Issue:13, Page: 43-52

Research Article

doi: 10.47072/demiryolu.794128

http://dergipark.org.tr/demiryolu

e-ISSN: 2687-2463, ISSN: 2149-1607

\title{
Demiryolu Altyapısı için Geçirimli Beton Boruların Tasarımı
}

\author{
Mehmet CANBAZ ${ }^{* 1} \odot$, Serhat ÇELIKTEN²® \\ ${ }^{1}$ Eskişehir Osmangazi Üniversitesi, Mühendislik Mimarlık Fakültesi, İnşaat Mühendisliği \\ Bölümü, Eskişehir, Türkiye \\ ${ }^{2}$ Nevşehir Hacı Bektaş Veli Üniversitesi, Mühendislik Mimarlık Fakültesi, İnşaat \\ Mühendisliği Bölümü, Nevşehir, Türkiye \\ *scelikten@nevsehir.edu.tr
}

(Alınış/Received: 12.09.2020, Kabul/Accepted: 27.10.2020, Yayımlama/Published: 31.01.2021)

\begin{abstract}
Öz: Demiryolu altyapısı, hem üzerine gelen hareketli yükleri taşıyacak kapasiteye sahip olmalı hem de üstyapının zarar görmemesi için yağmur sularını olabildiğince kısa sürede tahliye edebilecek şekilde tasarlanmalıdır. Teknolojik gelişmelerle birlikte demiryolu üstyapısı, sinyalizasyon sistemi gibi demiryolu trafiği için önemli sistemleri barındırmaktadır. Bu sistemlerin sağlıklı çalışabilmesi için de demiryoluna gelen yağmur ve sel sularının olabildiğince hızlı tahliyesi önem arz etmektedir. Bu çalışmada demiryolundan suyun hızlı bir şekilde tahliyesine katkıda bulunabilecek olan geçirimli beton boruların özellikleri araştırılmıştır. Bu amaçla, iki farklı çimento türü ve 400,450 ve $500 \mathrm{~kg} / \mathrm{m} 3$ olmak üzere üç farklı çimento dozajı ile geçirimli beton karışımları üretilmiş̧ir. Üretilen karışımlardan 4x4x16 cm boyutlarında prizma, $10 \mathrm{~cm}$ çapında $10 \mathrm{~cm}$ yüksekliğinde silindir ve $50 \mathrm{~cm}$ uzunluğunda $25 \mathrm{~cm}$ çapında $2.5 \mathrm{~cm}$ et kalınlığında beton boru numuneleri alınmıştır. Prizma numuneler üzerinde ultrases geçiş hızı, birim ağırlık, aşınma, basınç ve eğilme dayanımı; silindir numuneler üzerinde geçirimlilik ve beton boru numuneler üzerinde ise tepe yükü basınç dayanımı deneyleri gerçekleştirilmiştir. Deney sonuçları, 7-8 mm aralı̆̆ında kalker kökenli agregalar ile $18 \mathrm{kN} / \mathrm{m}$ tepe yükü basınç dayanımına ve $3.34 \mathrm{~cm} / \mathrm{sn}$ geçirimliliğe sahip geçirimli beton borular üretilebileceğini göstermiştir.
\end{abstract}

Anahtar kelimeler: Altyapı, Geçirimli Beton Boru, Geçirimlilik Katsayısı, Tepe Yükü

\section{Design of Permeable Concrete Pipes for Railway Infrastructure}

Abstract: The railway infrastructure should be designed to have the capacity to carry the live loads on it and to discharge rain water as short as possible in order not to damage the superstructure. Along with technological developments, railway superstructure contains important systems for railway traffic such as the signaling system. In order for these systems to work properly, the evacuation of rain and flood waters coming to the railway as quickly as possible is important. In this study, the properties of permeable concrete pipes that can contribute to the rapid evacuation of water from the railway were investigated. For this purpose, permeable concrete mixtures were produced with two different cement types and three different cement dosages: 400, 450 and $500 \mathrm{~kg} / \mathrm{m} 3$. Specimens of $4 \times 4 \times 16 \mathrm{~cm}$ prism, $10 \mathrm{~cm}$ diameter $10 \mathrm{~cm}$ high cylinder and $50 \mathrm{~cm}$ length $25 \mathrm{~cm}$ diameter $2.5 \mathrm{~cm}$ wall thickness concrete pipe samples were taken from the produced mixtures. Ultrasound velocity, Unit weight, abrasion, compressive and flexural strength tests were carried out on the prism specimens, permeability tests were carried out on the cylindrical specimens and the peak load strength tests were conducted on the concrete pipe specimens. The experiment results showed that and permeable concrete pipes with $18 \mathrm{kN} / \mathrm{m}$ peak load compressive strength and $3.34 \mathrm{~cm} / \mathrm{sec}$ permeability can be produced with the 7-8 $\mathrm{mm}$ limestone origin aggregates.

Keywords: Infrastructure, Permeable Concrete Pipe, Permeability Coefficient, Peak Load 


\section{Giriş}

Nüfus artışı, hızlı şehirleşme ve yapılaşma sebebiyle doğal kaynakların tüketimi ve bu tüketim ile ortaya çıkan problemler gün geçtikçe artmaktadır. Bu sebeple, bilim adamları ve teknik elemanlar bu problemlere çözüm bulabilmek için farklı yöntemler geliştirme arayışındadırlar. Şehirleşme ile azalan geçirimsiz yüzey alanı bu problemlerden biridir. Toprağa aktarılamayan yağmur sularının hızlı drene edilmesine ve toprak altı katmanlara aktarmaya yardımcı olan özel bir beton türü olan geçirimli beton da bu problemin çözümünde yenilikçi bir alternatiftir [1]. Geçirimli beton, yol kaplaması ile araç lastiği arasında yağmur suları sebebiyle meydana gelen sesi azaltma, kentsel 1s1 adas1 etkilerini azaltma ve yeraltı sularına karışması muhtemel kirleticileri kısmen tutma gibi çeşitli ekolojik yararları nedeniyle günümüzde daha fazla tercih edilir hale gelmiştir [2-4]. $\mathrm{Bu}$ çevresel faydaları sebebiyle geçirimli betonlar günümüzde otoparklarda, garaj yollarında, tali yollarda, kaldırımlarda ve yürüyüş yollarında tercih edilmekte ve kullanımı gün geçtikçe artmaktadır [5]. Geçirimli betonlar özellikle açık gözenek yapısı nedeniyle sürdürülebilir bir malzeme olarak değerlendirilir ve pozitif çoğu özelliği açık gözenek yapısına atfedilir. Bu yapı, beton bünyesindeki boşlukların makro boyutta ve birbirleriyle bağlantılı olmasıyla ilişkilidir. Bu yapı genellikle kesikli gradasyona sahip iri agregalar ile elde edilebilmektedir [6].

Yapılaşma sonucu yerleşim yerlerinin beton ile kaplanması, yağış sırasında toprağın su ile buluşamamasına ve yüzeysel akışın artmasına neden olmuştur. Su döngüsünün doğal halinin bozulması beraberinde selleri de arttırmış ve mevcut drenaj sistemleri yetersiz kalmıştır. Bu durum Şekil 1'den de görüldügüü gibi şehir içinde giderek artan raylı sistemleri de etkilemekte işletilemez hale getirmektedir. Son yıllarda bu duruma çözüm olarak geliştirilen geçirimli beton uygulamaları önem kazanmıştır.
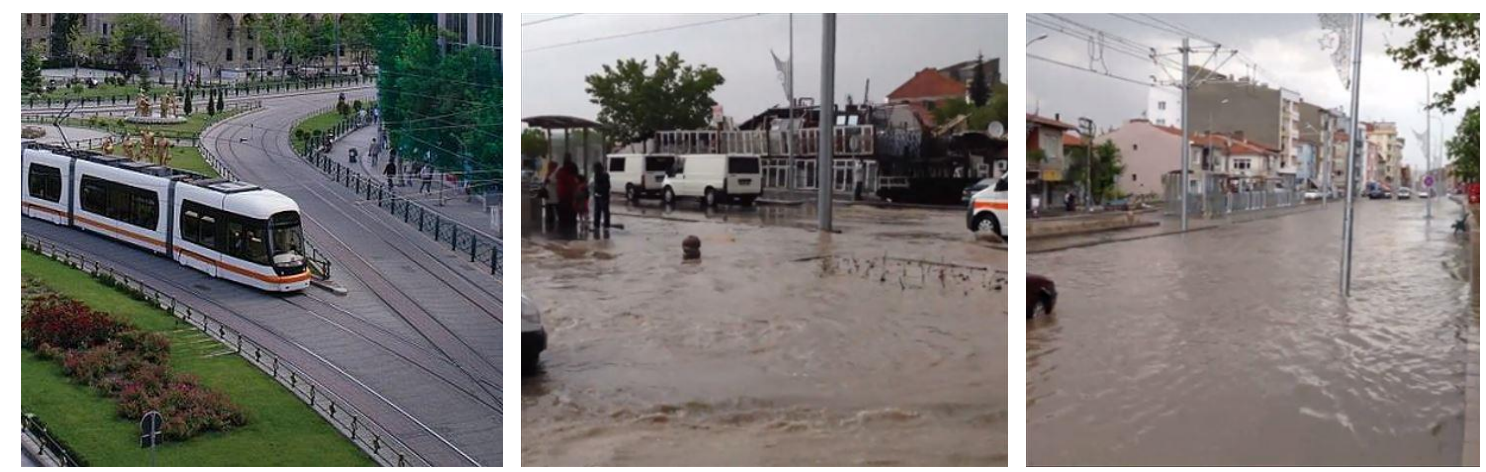

Şekil 1. Şehir içi raylı sistemler ve kuvvetli yağış sonrası drenaj sistemi sorunları [7]

Geçirimli beton Şekil 2'den de görüldüğü gibi ince agrega kullanılmayan betondur. Geçirimli beton uygulaması ile yağış sırasında geçirimli betondan geçen su toprak tarafindan emilmektedir. Ancak yağışın uzun sürmesi toprağı doygunluğa ulaştırabilmekte ve yüzeysel akışı arttırabilmektedir. Bu su drenaj sistemlerine ulaştırılmaktadır. Ancak yağmur suyu drenajı için kullanılan boru çapları ne kadar artırılsa da yeterli gelmemekte ve yüzey suyunun oluşmasına neden olmaktadır. Bu durum raylı sistem taşımacılığını etkilemektedir. Bu çalışmada geçirimsiz olarak üretilen beton borular yerine geçirimli beton boru kullanılması önerilmiştir. Böylece yer altında su iletimi sırasında doygunluğa ulaşmamış bölgelerde toprak tarafından su emilebilmekte ve iletilen su miktarının daha kontrollü artması ile tahliye sağlanmış olacaktır. Ancak geçirimli betonun su drenaj performansı, betonun geçirimliliğinin yanında alt tabakanın geçirimliliğine de bağlıdır. Killi bir zeminde suyun zeminin alt tabakalarına ulaşması betonun geçirimli bile olsa kolay olmayacaktır. Doygunluğu beklemeden su birikecektir. Bu açıdan geçirimli boru kullanılması sistem olarak drenaj için faydalı olabilir. Yoğun yağışlı havalarda daha fazla kullanılan toplu taşıma aksamamış olacak ve yüzeyde su birikintilerin olmaması konforu arttıracaktır. 

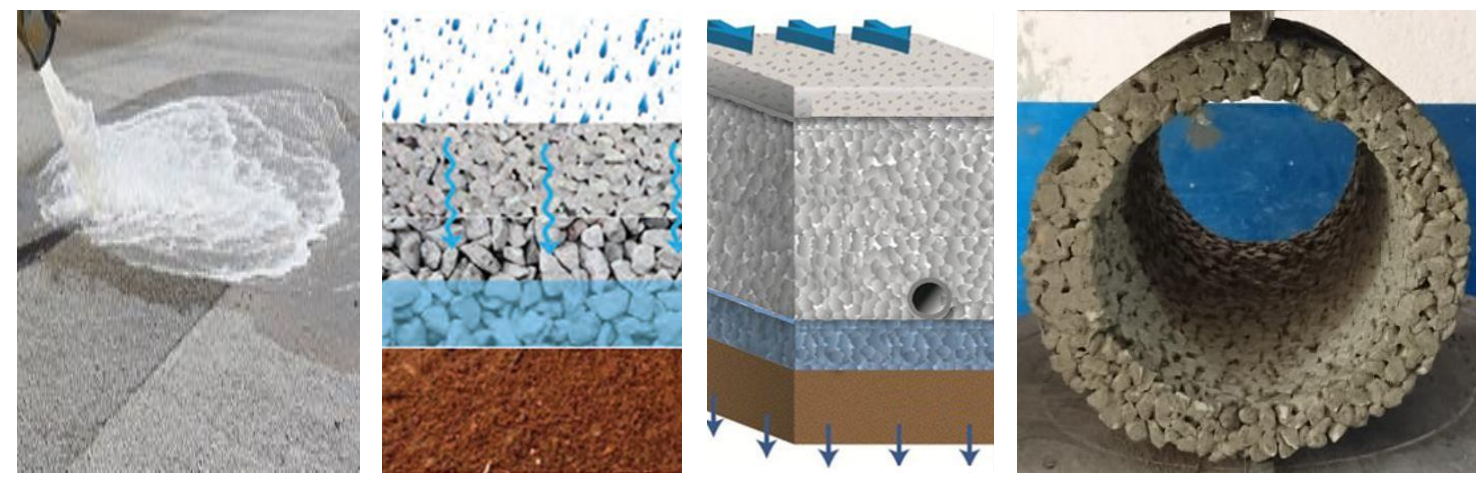

Şekil 2. Geçirimli beton uygulamaları $[8,9]$

Geçirimli betonda kullanılan bağlayıcı miktarı ve türü ile agrega miktarı, gradasyonu ve türü geçirimli betonların niteliklerini etkileyen önemli parametrelerdir. Kesikli gradasyonu elde edebilmek ve makro boşluk miktarını artırabilmek için daha önce yapılan bazı deneysel çalışmalarda ince agrega miktarı azaltma yoluna gidilmiştir $[10,11]$. Bununla birlikte, yapılan araştırmalarla, ince agrega içeriğinin geçirimli betonların aşınma dayanıklılığını ve donmaçözülme dayanıklılığını geliştirdiği sonucuna ulaşılmıştır [12-14]. Bu çalışmada da 7-8 mm boyut aralığındaki kalker agregaları ile prizma, silindir ve boru şeklindeki numuneler üretilmiştir. Üretilen geçirimli beton karışımlarının birim ağırlık, ultrases geçiş hızı, eğilme ve basınç dayanımı, aşınma, geçirimlilik özellikleri araştırılmıştır. Ayrıca, araştırılan özellikler üzerinde çimento türünün ve dozajının etkileri irdelenmiştir.

\section{Deneysel Çalışma}

\subsection{Kullanilan malzemeler}

Geçirimli boru üretiminde bağlayıcı olarak özelikleri Tablo 1'de verilen CEM I 42.5R ve CEM IV/B (P) $32.5 \mathrm{~N}$ çimentoları ayrı ayrı kullanılmıştır. Puzolanik çimentoda puzolan \% 40 oranında kullanılmıştır. $\mathrm{Bu} \% 40$ puzolanın \% 70'i vitrifiye kırı̆̆ı, \% 30’u ise trastır. Kalker kökenli kırmataşlar önce $7 \mathrm{~mm}$ ve $8 \mathrm{~mm}$ eleklerden elenmiştir. Üretimde 7-8 $\mathrm{mm}$ tane boyutuna sahip bu agregalar kullanılmıştır. Karışımlarda, şehir şebeke suyu kullanılmıştır. Kullanılan su, içilebilir nitelikte olduğundan, beton karışımlarına zarar verebilecek iyonlar içermemektedir.

Tablo 1. Çimentoların fiziksel özellikleri ve kimyasal kompozisyonu

\begin{tabular}{lcclcc}
\hline & CEM & CEM & CEM & CEM \\
& IV/B(P)32.5N & I42.5R & IV/B(P)32.5N & I42.5R \\
\hline $\mathrm{SiO}_{2}, \%$ & 38.0 & 19.2 & Yoğunluk, g/cm & 2.87 & 3.09 \\
$\mathrm{Al}_{2} \mathrm{O}_{3}, \%$ & 9.68 & 4.56 & Blaine Özgül Yüzey, cm $/ \mathrm{g}$ & 3590 & 4450 \\
$\mathrm{Fe}_{2} \mathrm{O}_{3}, \%$ & 2.91 & 3.09 & Priz Başlama, dk & 190 & 163 \\
$\mathrm{CaO}, \%$ & 32.2 & 62.9 & Priz Bitiş, dk & 270 & 228 \\
$\mathrm{SO}_{3}, \%$ & 2.06 & 3.21 & Basınç Dayanımı, MPa & 38.1 & 52.1 \\
\hline
\end{tabular}

\subsection{Metot}

Üretimde agreganın sıkışmış birim ağırlığı dikkate alınmıştır. Karışım oranları $1 \mathrm{~m}^{3}$ için $1310 \mathrm{~kg}$ 7-8 mm kırmataş, dozaj olarak da 400, 450, $500 \mathrm{~kg}$ seçilmiştir. Deneme üretimlerinde daha az çimento oranlarında boruların dayanımlarının düştüğü, daha fazla çimento oranında ise yeterli geçirimliliğin elde edilemediği görülmüştür. Su-çimento oranı 0.4 olarak belirlenmiştir. Üretilen dozaja göre 3 tip geçirimli betondan $4 \mathrm{~cm} \mathrm{x} 4 \mathrm{~cm}$ x $16 \mathrm{~cm}$ boyutlarına sahip prizmatik numuneler, 
$10 \mathrm{~cm}$ çapında $10 \mathrm{~cm}$ yüksekliğinde silindir numuneler ve $50 \mathrm{~cm}$ uzunluğunda $25 \mathrm{~cm}$ çapında 2.5 $\mathrm{cm}$ et kalınlığında beton boru numuneleri alınmıştır. Numuneler standart kür ortamında $23 \pm 2{ }^{\circ} \mathrm{C}$ sicaklığa sahip kirece doygun suda bekletilmiştir. Prizmatik numuneler üzerinde yapılan deneyler ile numunelerin birim ağırlıkları, ultrases geçiş hızları, aşınma kayıpları, TS EN 196-1 standardına göre eğilme ve basınç dayanımları belirlenmiştir. Aşınma deneyi TS 699'a göre yapılmıştır. Ancak uygun kalıp bulunamadığı için bu standartta belirtilen $50 \mathrm{~cm}^{2}$ kesitli numune kullanılmamıştır. Numunelerin boşluklu yapısı yükseklik azalması veya hacimce azalma için sağlıklı sonuçlar vermediğinden, numuneler aşınma deneyi öncesinde ve sonrasında tartılarak ağırlıkça aşınma kayıpları belirlenmiştir. Silindir üzerinde yapılan geçirimlilik deneyi ile hidrolik iletkenlikleri belirlenmiştir. Şekil 3'te görüldüğü gibi beton borular üzerinde tepe basınç deneyi ile tepe basınç yükleri belirlenmiştir. Her bir deney üç numune üzerinde yapılmıştır.
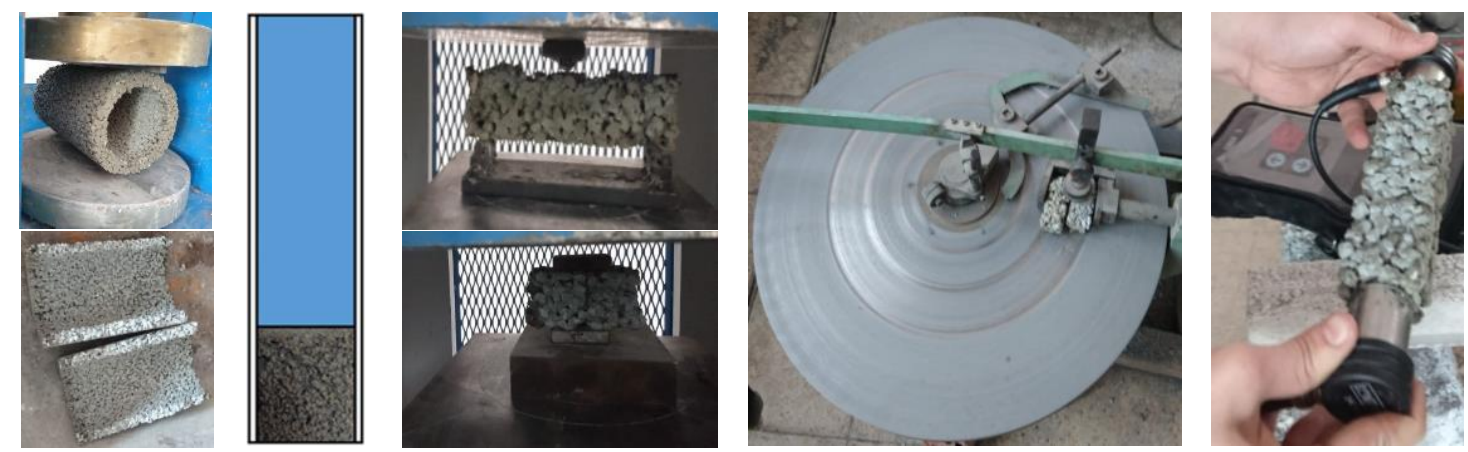

Şekil 3. Üretilen geçirimli borular ve geçirimli betonlar üzerinde yapılan deneyler

\section{Tartışma}

Üretilen geçirimli beton karışımlarından alınan prizmatik numunelerin birim ağırlık değişimleri Şekil 4'te verilmiştir. Dozajın artması ile betonların birim ağırlık değerleri \% 13'e ulaşan oranlarda artmıştır. Geçirimli betonda agrega çevresinde ve boşluklardaki çimento miktarının artması birim ağırlığın artmasına neden olmuştur. Katkılı çimento kullanılması durumunda ise birim ağırlık normal Portland çimentosu ile üretilen numunelere göre \% 4'e ulaşan oranlarda azalmıştır. Katkılı çimentoların yoğunluğunun normal Portland çimentolarına göre daha az oluşu birim ağıllıkta azalmaya sebep olmuştur.

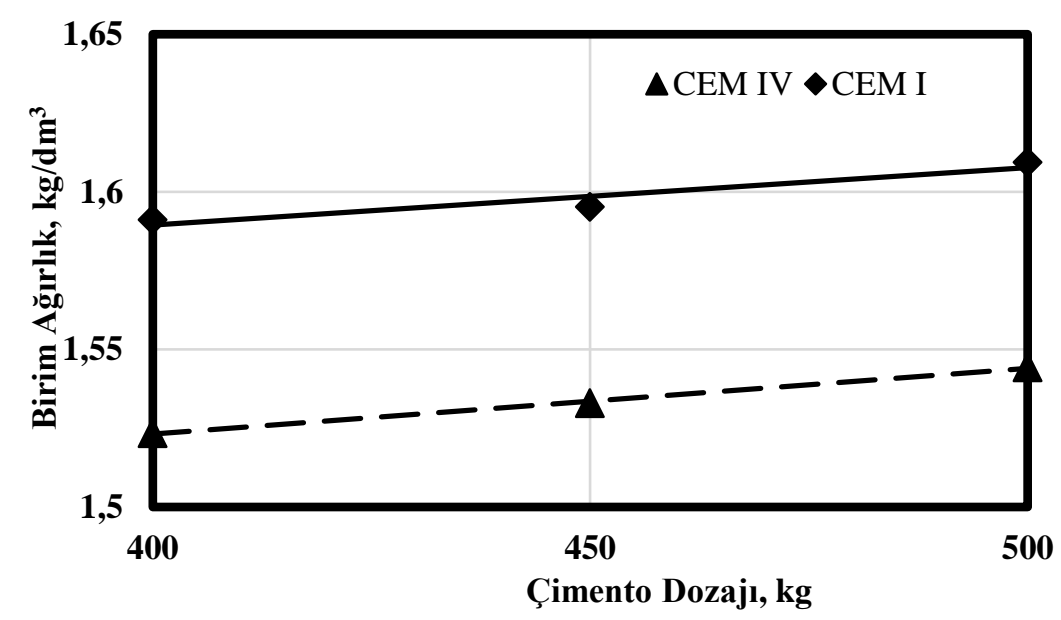

Şekil 4. Birim ağırlık deney sonuçları

Üretilen geçirimli betonların dozaja bağlı olarak ultrases geçiş hızı değişimleri Şekil 5'te verilmiştir. Katkılı çimento kullanılarak üretilen betonlarda dozajın artması ultrases geçiş 
hızlarını \% 1.5'e ulaşan oranda arttırırken, katkısız çimento kullanılması durumunda artış oranı \% 9'a ulaşmıştır. Çimento miktarının artışı ile boşluğun azalması ultrases geçiş hızlarının artmasına neden olmuştur. Çimento türü dikkate alındığında katkılı çimento kullanılması durumunda ultrases geçiş hızları \% 30'a ulaşan oranda azalmıştır. Katkısız çimentonun inceliğinin daha fazla olması ultrases geçiş hızlarının daha yüksek elde edilmesine neden olmuştur.

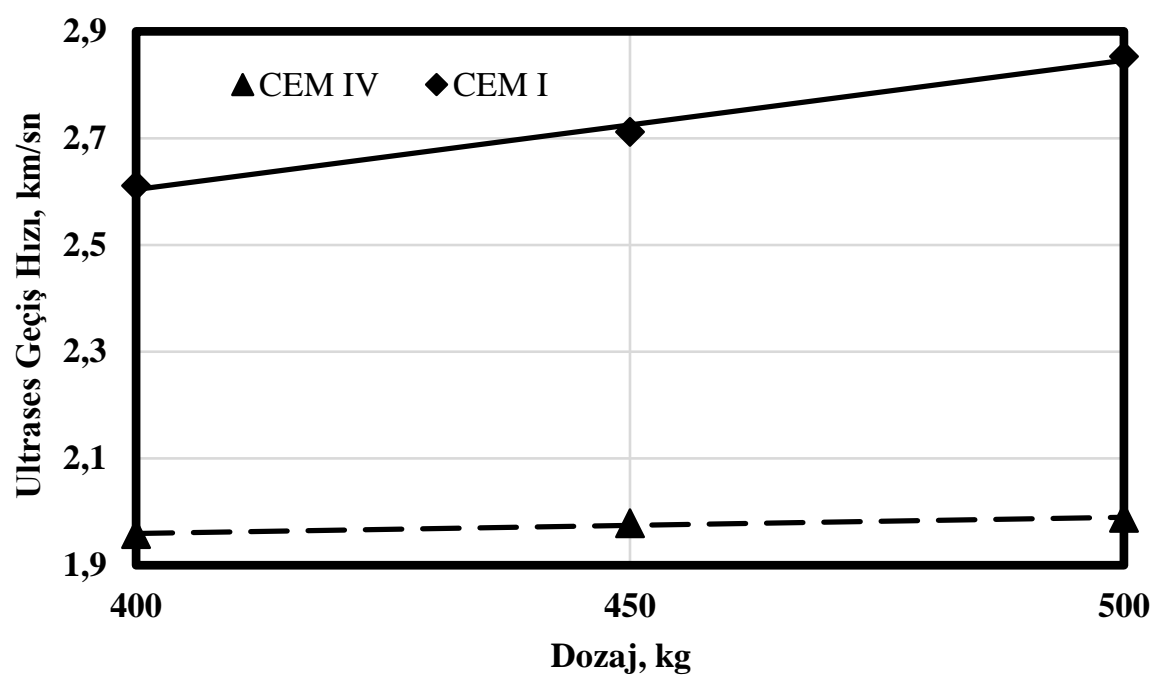

Şekil 5. Üretilen numunelerin ultrases geçiş hızları

Suyun tahliyesi için geçirimli betonlarda hidrolik iletkenliğin belirlenmesi önemlidir. Üretilen geçirimli beton numunelerin hidrolik iletkenlikleri Şekil 6'da verilmiştir. Betonlarda dozajın artması ile boşluk miktarının azalmış ve hidrolik iletkenlikleri de kademeli olarak azalmıştır. Katkılı çimento ile üretilen betonlarda çimento dozajının artışı geçirimlilik katsayısını \% 5.9'e uluşan oranda azaltırken, normal Portland çimentosu ile üretilen betonlarda azalma oranı $\% 8.5$ olmuştur. Çimento türleri karşılaştırıldığında mineral katkı içeren çimentolarla üretilen betonların hidrolik iletkenliği \% 4'e ulaşan oranda daha fazla elde edilmiştir. Yapılan çalışmalarda agrega tane boyutunun dar aralıkta tutulması, hidrolik olarak daha iletken betonlar elde etmeyi sağlamıştır [15].

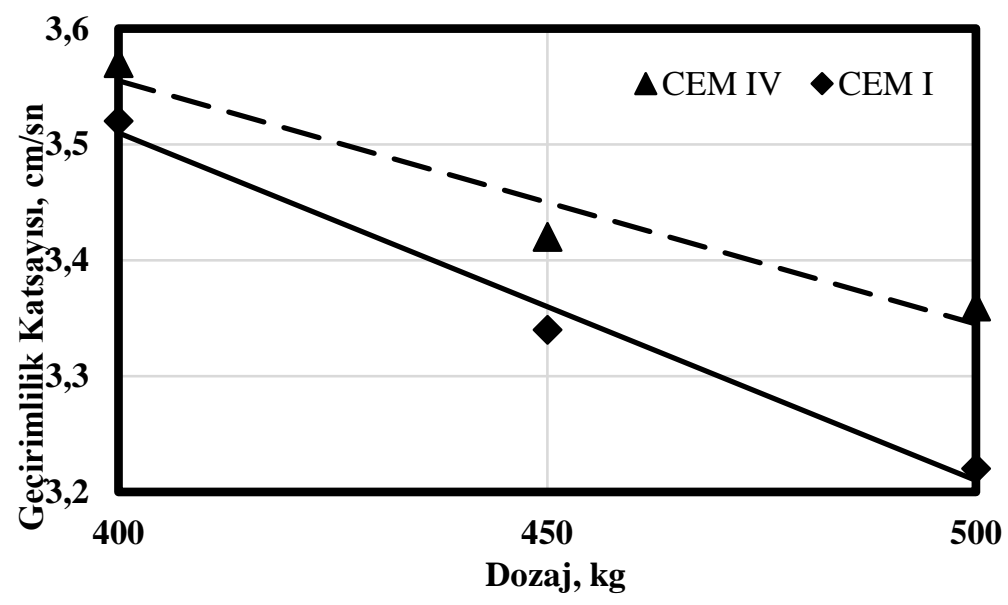

Şekil 6. Üretilen silindir numunelerin hidrolik iletkenlikleri 
Yapılan bir çalışmada geçirimli betonun geçirebileceği yağış miktarı Tablo 2'deki gibi hesaplanmıştır [15]. Bu çalışmada üretilen geçirimli betonların hidrolik iletkenlikleri dikkate alındığında en az $1800 \mathrm{~mm} / \mathrm{dk}$ gibi yoğun bir yağışı geçirebileceği görülmüştür. Karşılaşılabilecek en yüksek yağış miktarı olarak $38 \mathrm{~mm} / \mathrm{dk}$ değerlendirildiğinde, [15] bu çalışmada elde edilen geçirimli betonların hem anlık şiddetli yağışı hem de çevreden gelen yüzeysel akıntıları alt tabakalara aktarabileceği ve üst tabakalarda su ceplerine izin vermeyeceği söylenebilir.

Tablo 2. Geçirimli betonların alt tabakalara iletebileceği yağış miktarları

\begin{tabular}{cc}
\hline $\begin{array}{c}\text { Geçirimlilik katsayısı, } \\
\mathrm{cm} / \mathrm{sn}\end{array}$ & $\begin{array}{c}\text { Alt tabakalara iletebileceği yağ } / s ̧, ~ \\
\mathrm{~mm} / \mathrm{dk}\end{array}$ \\
\hline 3 & 1800 \\
3.5 & 2100 \\
4 & 2400 \\
\hline
\end{tabular}

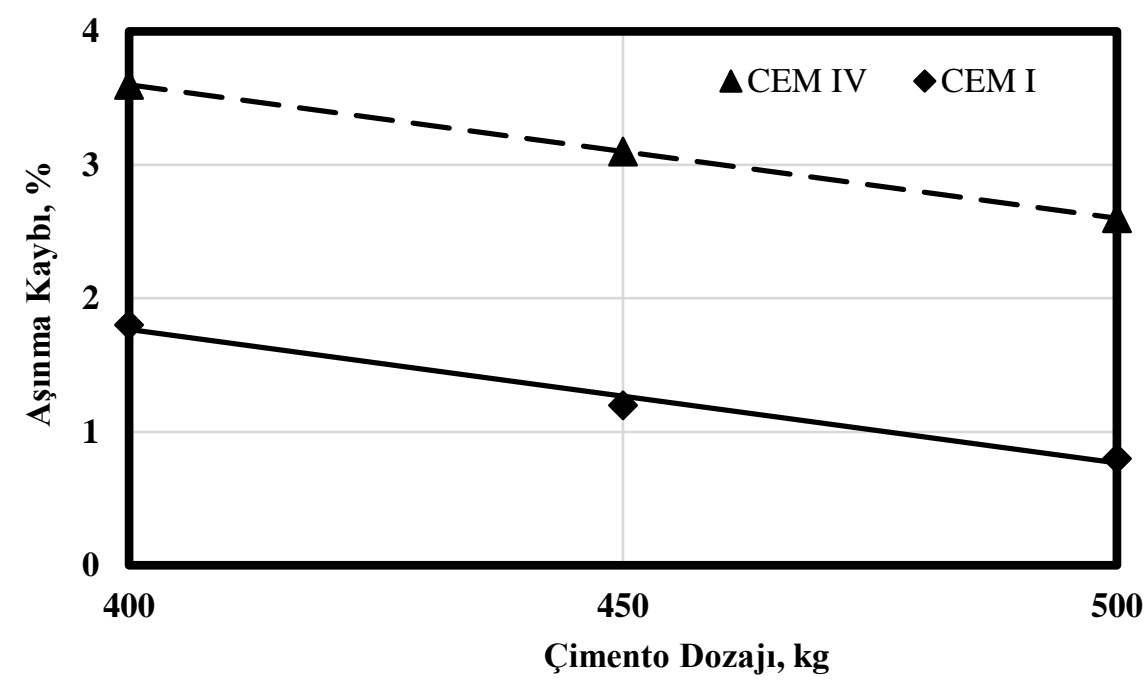

Şekil 7. Geçirimli betonların Dorry cihazı ile ölçülen aşınma kayıpları

Raylı sistemlerde yaya yollarında veya yük taşıma kısımlarında kullanılan araçlar betonları aşındırabilmektedir. Ayrıca bu çalışmanın konusu olan geçirimli borularda suyun akışı yüzeyde sürtünme etkisi oluşturarak aşınmaya neden olabilmektedir. Bu amaçla bu betonlar aşınmaya dayanıklı olmalıdır. Üretilen geçirimli beton numunelerin aşınma kayıpları Şekil 7'de verilmiştir. Şekil 7 incelendiğinde dozajın artması aşınma kayıplarını azalmıştır. Katkılı çimento kullanılması durumunda aşınma kayıpları dozaj atışı ile aşınma kayıpları \% 27 azalırken, normal Portland çimentosu kullanılması durumunda bu azalma oranı \% 55 olmuştur. Katkılı çimento ile katkısız çimento kıyaslandığında ise katkılı çimento kullanılması durumunda aşınma kayıpları 2.2 kata ulaşan oranda artmıştır. Daha ince olan normal Portland çimentosu kullanılması durumunda dozajın artışı ile hidratasyon ürünleri de artmış daha iyi bağlayıcılık sağlayarak rijitliği arttırmış ve aşınma kayıplarını azaltmıştır. 


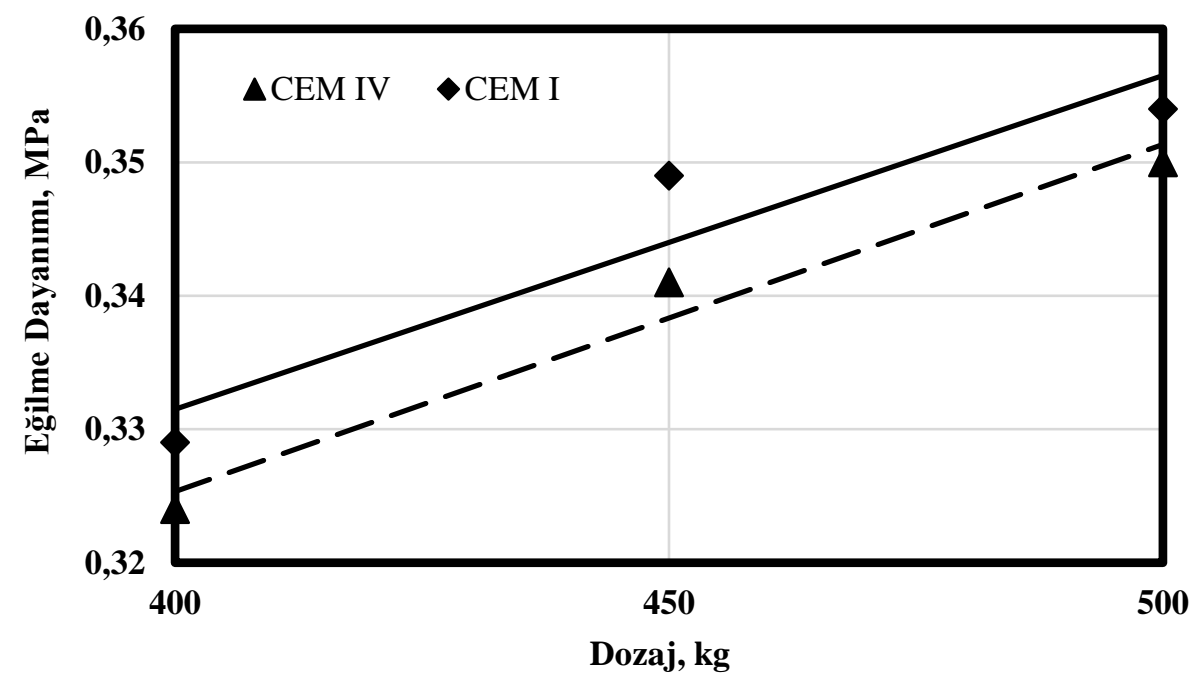

Şekil 8. Geçirimli beton numunelerin eğilme dayanımları

Demiryolu sanat yapı elemanları eğilme kuvveti etkisinde kalabilmektedir. Üretilen geçirimli betonların eğilme dayanımlarının belirlenmesi bu nedenle önemlidir. Geçirimli beton karışımlarından alınan numunelerin eğilme dayanımları Şekil 8'de verilmiştir. Dozajın artması ile eğilme dayanımları \% 8'e ulaşan oranda artmıştır. Katkılı çimento kullanılması durumunda ise eğilme dayanımları \% 2 civarında azalmıştır. Bağlayıcı oranının artması agregaların daha iyi bağlanmasına ve eğilme etkisinde dayanımın artmasına neden olmuştur.

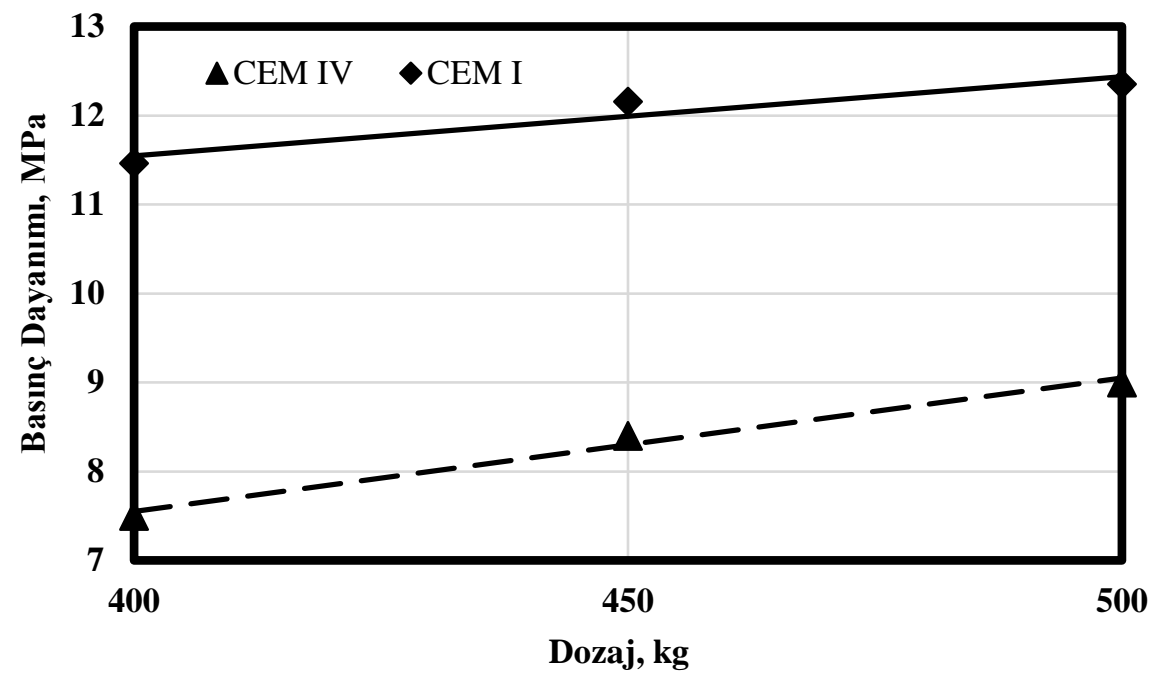

Şekil 9. Basınç dayanımlarının dozaj ile değişimi

Betonun sınıflandırılmasında kullanılan ve en önemli mekanik özelliği olan basınç dayanımları üretilen geçirimli betonlar için Şekil 9' da verilmiştir. Ancak henüz geçirimli betonlar için standart bir sınıflandırma yapılmamıştır. Şekil 9 incelendiğinde dozaj artışı ile katkısız çimento kullanılan geçirimli betonlarda basınç dayanımı \% 7.7'ye ulaşan oranda, CEM IV/B (P) $32.5 \mathrm{~N}$ çimento kullanılması halinde ise \% 20'ye ulaşan oranda artmıştır. Katkı kullanılmayan çimentonun nominal dayanımının katkılıya göre daha yüksek olması geçirimli beton numunelerinin dayanımlarında \% 34'e ulaşan oranda artışa neden olmuştur. 


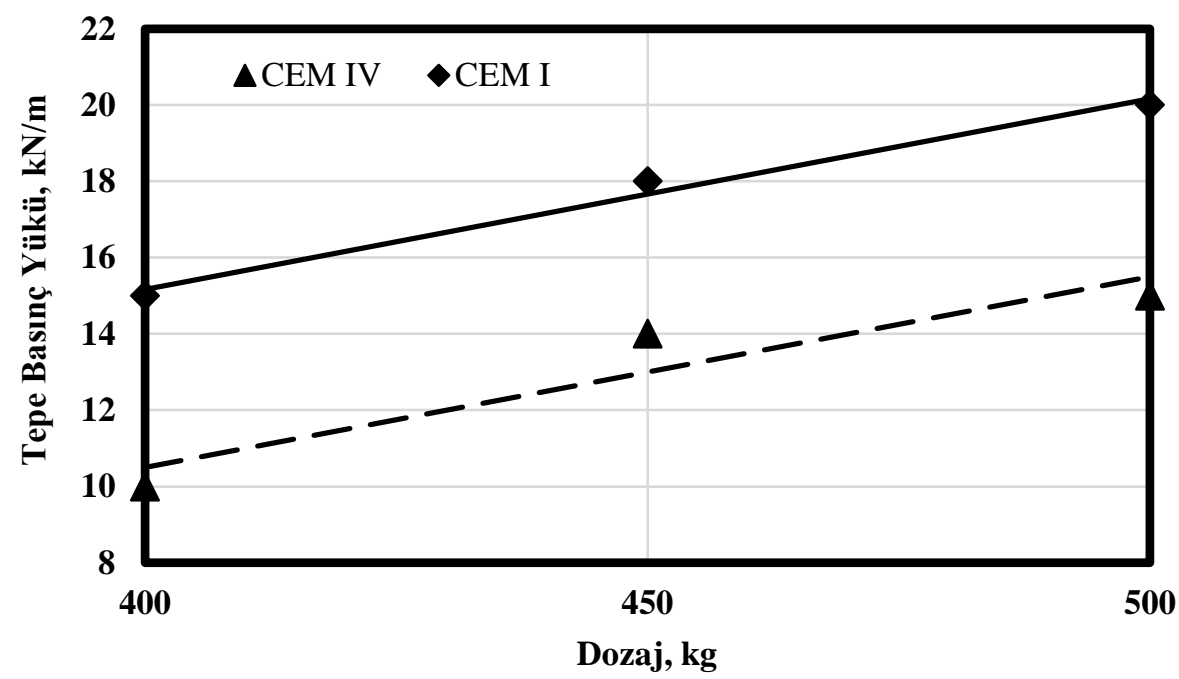

Şekil 10. Geçirimli beton boruların tepe basınç yükleri

Beton borularda mekanik özeliklerden tepe basınç yükü dikkate alınmaktadır. Beton borular tepe basınç yüklerine göre mekanik olarak sınıflara ayrılabilmektedir. Üretilen geçirimli beton boruların tepe basınç kuvveti değişimleri Şekil 10'da verilmiştir. Şekil 10 incelendiğinde katkılı çimento kullanılan numunelerde dozaj artışı ile tepe basınç yükleri \% 50'ye ulaşan oranda artarken, normal Portland çimentosu kullanılan betonlarda dozaj artışı ile bu oran \% 33 olmuştur. Dozaj artışından bağımsız olarak çimento türü dikkate alındığında katkılı çimento yerine normal Portland çimentosu kullanılması durumunda tepe basınç yükleri \% 33'e ulaşan oranda artmıştır. Geçirimli betonların tepe basınç kuvvetlerinde bağlayıcı oranı, inceliği ve mineral katkı içerip içermediği etkili olduğu bu çalışma sonucunda görülmüştür. Tepe basınç yükü deneyleri sırasında numune üzerine etkiyen kuvvetler altında beton borulardan beklenildiği gibi gevrek olarak kırılma gözlenmediği, gözle görülebilen önemli miktarda şekil değiştirme yaptı̆̆ı belirlenmiştir.

\section{Sonuç}

Çimento dozajının, çimento türünün geçirimli beton ve geçirimli beton boru özeliklerine etkisinin araştırıldığ bu çalışma sonucunda:

- Dozajın artması geçirimli betonların birim ağırlığında ve ultrases geçiş hızında artmaya neden olurken, puzolanlı çimento kullanımı birim ağırlığı ve ultrases geçiş hızını düşürmüştür.

- Dozajın artışı numunelerin hidrolik iletkenliğini ve aşınma kaybını azaltırken, katkılı çimento kullanılması hidrolik iletkenliği ve aşınma kaybını arttırmıştır.

- Geçirimli beton üretiminde kullanılan çimento miktarını artışı eğilme ve basınç dayanımını arttırırken, üretimde puzolanlı çimento kullanılması durumunda puzolan kullanılmayan çimentoya göre eğilme ve basınç dayanımın azaldığı görülmüştür.

- Geçirimli beton borular üzerinde yapılan tepe basınç deneyinde dozaj artışı ile tepe basınç yüklerinin arttığ 1 görülmüsstür. Çimento türünün de tepe basınç yükü değişimlerinde etkili olduğu görülmüştür. 


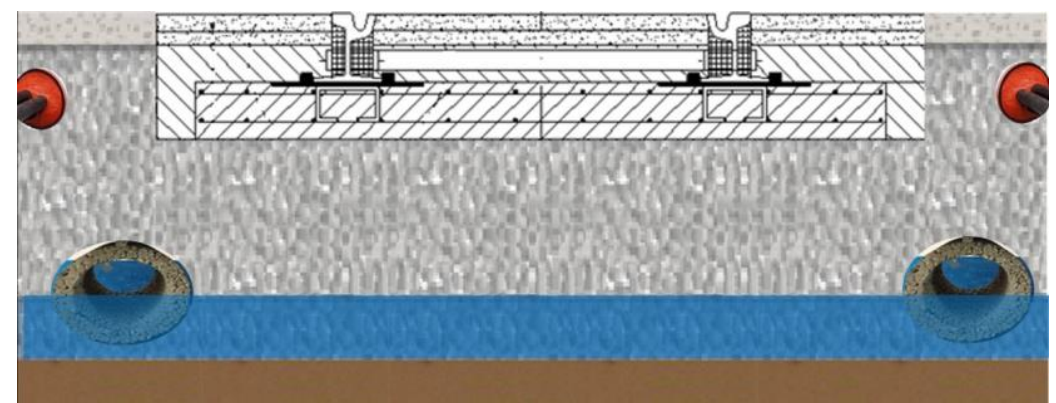

Şekil 11. Raylı sistemlerde geçirimli beton ve geçirimli boru uygulaması

Yapılan deneyler sonunda 7-8 mm aralığında agrega kullanılması durumunda, geçirimli beton boru üretiminde $400-500 \mathrm{~kg} / \mathrm{m}^{3}$ çimento kullanılması önerilir. Şekil 11'den de görüldüğg̈ gibi raylı sistemlerde geçirimli beton ve geçirimli boru kullanılması önerilir. Burada kullanılan oyuklu ray uygulaması kesiti Zhekov ve Iontchev yaptığı çalışmadan alınmıştır [16]. Özellikle yağışla birlikte ortamda serbestçe boşaltılabilecek suyun olması yeraltındaki enerji ve iletişim hatlarına zarar vermemesi için şekilde görüldügü gibi yalıtılarak kullanılması önerilir. Bu çalışmada durabilite etkileri dikkate alınmamıştır, daha sonraki çalışmalar için bu betonların durabilite özeliklerinin belirlenmesi önerilir.

\section{Kaynakça}

[1] A. Anzecc, "Australian and New Zealand guidelines for fresh and marine water quality," Australian and New Zealand Environment and Conservation Council and Agriculture and Resource Management Council of Australia and New Zealand, Canberra, pp. 1-103, 2000.

[2] Pervious Concrete, ACI 522R-06, American Concrete Institute Committee, 2006.

[3] N. Neithalath, M. S. Sumanasooriya, O. Deo, "Characterizing pore volume, sizes, and connectivity in pervious concretes for permeability prediction," Mater. Charact., vol. 61, no. 8, pp. 802-813, 2010, doi:10.1016/j.matchar.2010.05.004

[4] P. D. Tennis, M. L. Leming, D. J. Akers, Pervious concrete pavements (No. PCA Serial No. 2828) Skokie IL: Portland Cement Association, 2004.

[5] D. H. Nguyen, N. Sebaibi, M. Boutouil, L. Leleyter, F. Baraud, "A modified method for the design of pervious concrete mix," Constr Build Mater., vol. 73, pp. 271-282, 2014, doi: 10.1016/j.conbuildmat.2014.09.088

[6] S. Hesami, S. Ahmadi, M. Nematzadeh, "Effects of rice husk ash and fiber on mechanical properties of pervious concrete pavement," Constr Build Mater., vol. 53, pp. 680-691, 2014, doi:10.1016/j.conbuildmat.2013.11.070

[7] Rayhaber, "Eskişehir 3. aşama tramvay projesinin yüzde 90’` tamamlandı," [Online]. Available: https://rayhaber.com/2019/02/eskisehir-3-asama-tramvay-projesinin-yuzde-90i-tamamlandi/ [Accessed: 01.02.2019]

[8] S. Uçar, A. Ö. Tarhan, "Geçirimli beton uygulama kılavuzu," T.C. Çevre ve Şehircilik Bakanlı̆̆l, Türkiye Hazır Beton Birliği, Yüksek Fen Kurulu Başkanlı̆̆l, pp. 28, 2018.

[9] Tecnical brochure, "Pervious concrete," Chaney Enterprises, pp.8, 2018.

[10] M. Sonebi, M. T. Bassuoni, "Investigating the effect of mixture design parameters on pervious concrete by statistical modelling," Constr Build Mater., vol. 38, pp. 147-154, 2013, doi: 10.1016/j.conbuildmat.2012.07.044

[11] A. Torres, J. Hu, A. Ramos, "The effect of the cementitious paste thickness on the performance of pervious concrete," Constr Build Mater., vol. 95, pp. 850-859, 2015, doi: 10.1016/j.conbuildmat.2015.07.187

[12] J. T. Kevern, V. R. Schaefer, K. Wang, M. T. Suleiman, "Pervious concrete mixture proportions for improved freeze-thaw durability," J. ASTM Int., vol. 5, no. 2, pp. 1-12, 2008, doi:10.1520/JAI101320

[13]K. Wang, V. R., Schaefer, J. T. Kevern, M. T. Suleiman,. "Development of mix proportion for functional and durable pervious concrete," In NRMCA Concrete Technology Forum: Focus on Pervious Concrete, pp. 1-12, 2006. 
[14] A. Bonicelli, F. Giustozzi, M. Crispino, "Experimental study on the effects of fine sand addition on differentially compacted pervious concrete," Constr Build Mater, vol. 91, pp. 102-110, 2015, doi: 10.1016/j.conbuildmat.2015.05.012

[15] S. Çelikten, M. Canbaz, "Agrega tane boyutunun ve bağlayıcı türünün geçirimli beton özeliklerine etkisi," Eskişehir Teknik Üniversitesi Bilim ve Teknoloji Dergisi B-Teorik Bilimler, vol. 8, no. 2, pp. 171-181, 2020.

[16] V. Zhekov, E. Iontchev, "Assessment of the urban rail network based on the accelerations in the axle box of the tram," Proceedings of the 5th MAC, Prague, Czech Republic, 2015.

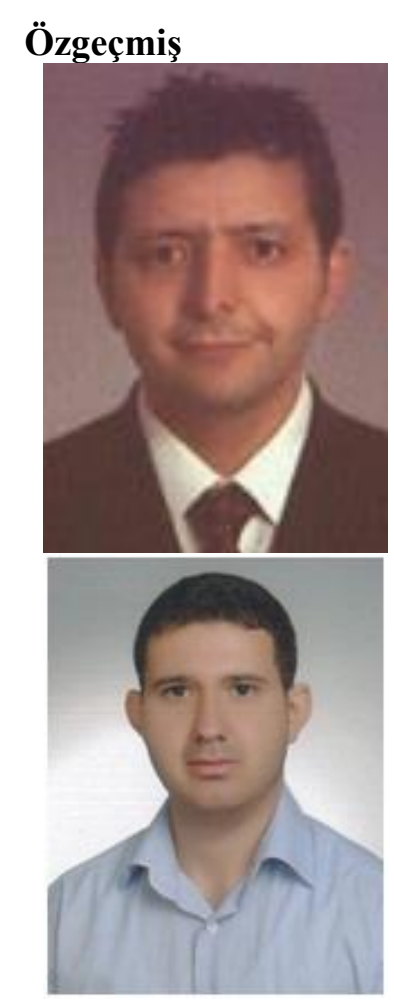

\section{Mehmet CANBAZ}

1998 y1lında YTÜ İnşaat Fakültesinden mezun oldu. Yüksek Lisansını Eskişehir Osmangazi Üniversitesi Fen Bilimleri Ensitüsü'nde yaptı. ESOGÜ Fen Bilimleri Ensitüsü'nde yaptığ1 doktorasını 2007'de tamamladı. Halen Osmangazi Üniversitesi, Mühendislik-Mimarlık Fakültesi, İnşaat Mühendisliği Bölümünde öğretim üyesi olarak görev yapmaktadır. Özel betonlar, endüstriyel atıkların beton teknolojisinde değerlendirilmesi ile ilgili çeşitli araştırmaları bulunmaktadır.

E-Posta:mcanbaz@ogu.edu.tr

\section{Serhat ÇELIKTTEN}

2011 yılında Gaziantep Üniversitesi İnşaat Mühendisliği Bölümü'nden mezun oldu. 2017-2019 yıllarında Anadolu Üniversitesi Ulaştırma Meslek Yüksekokulu'nda Öğretim Görevlisi olarak çalıştı. 2019 yılında Niğde Ömer Halisdemir Üniversitesi İnşaat Mühendisliği Anabilim Dalı'ndaki Doktora eğitimini tamamladı. 2020 yılında başladığı Nevşehir Hacı Bektaş Veli Üniversitesi, İnşaat Mühendisliği Bölümünde doktor öğretim üyeliği görevine devam etmektedir.

E-Posta: scelikten@nevsehir.edu.tr

\section{Beyanlar:}

Bu makalede bilimsel araştırma ve yayın etiğine uyulmuştur.

Tüm yazarların eşit oranda katkısı olmuştur. 